\title{
Detection of subsidence affecting civil engineering structures by using satellite InSAR
}

\author{
R Kauther Federal Waterways Engineering and Research Institute (BAW), Germany \\ R Schulze Federal Waterways Engineering and Research Institute (BAW), Germany
}

\begin{abstract}
Satellite interferometric synthetic aperture radar (InSAR) is an operational remote sensing technique for monitoring ground deformation. Advanced techniques to process radar data like persistent scatterer interferometry (PS-InSAR) combined with recently available high-resolution radar modes such as StripMap (SM) and spotlight, permit detection and measurement of vertical displacements in a range of subcentimetre to millimetre and unprecedented ground range resolution. Such features open up new fields of application in civil engineering projects. Now many objects distributed over large areas may be monitored, typically on an object size scale of 2 to $20 \mathrm{~m}$, with high measurement density and adequate accuracy.
\end{abstract}

We present an application of this technique on a navigation lock that was constructed in a karst region where bedrock is locally dissolved by groundwater flow, occasionally leading to sinkholes, surface subsidence and displacement of structures. For that reason, the lock complex has been under terrestrial geodetic survey for several decades. This set of readily available geodetic data has been used to validate the processed satellite InSAR data, acquired by two satellites (ERS and Envisat) during the time period ranging from 1992 to 2010. Encouraged by good agreement of the geodetic and satellite measurements, in a second step TerraSAR-X data taken in SM mode has been processed to increase ground resolution. To assess further improvements in resolution the newly available TerraSAR-X High-Resolution Spotlight (HS) mode is investigated.

It can be concluded that InSAR data (ERS and Envisat) reaching back to 1991/1992 may be used to gain information on subsidence effects like using a rear view mirror. However, significant limitations in resolution need to be taken into account. Comparing remotely sensed data using TerraSAR-X (SM) mode to in situ measurements of deformation, it is too early for a 1:1 validation of the very small deformation measured in situ based on 17 months of observation. Nevertheless, it can be stated that no conflicting measurements have been observed and that several areas associated with larger deformations were clearly detected.

In our opinion, such approaches may improve the quality of site investigation by focusing further terrestrial geodetic and geotechnical monitoring on such pre-selected locations, especially for operational monitoring of civil engineering applications.

\section{Introduction}

Spaceborne interferometric synthetic aperture radar (InSAR) is an imaging radar technique, used to measure deformations of the earth's surface over large areas. It was originally developed to detect land subsidence associated with e.g. volcanic activity, earthquakes or water extraction from aquifers. Satellites such as ERS-1, ERS-2 and Envisat which were operational from 1991 to 2010 collected large data sets readily available free of cost. Meanwhile, advanced techniques such as persistent scatterer interferometry (PS-InSAR or PSI) combined with recently available high resolution and very high resolution radar modes of civilian satellites such as TerraSAR-X (TSX) and Cosmo-SkyMed permit detection and measurement of vertical displacements in a range of sub-centimetre to millimetre and unprecedented ground range resolution.

These satellite developments, which increased the quantity of persistent scatterer (PS) according to Gernhardt et al. (2012) by a factor of 100 to 200 compared to ERS or Envisat, opened up new fields of 
application in civil engineering projects. Fornaro et al. (2013) report on thermal dilation monitoring of a bridge construction and Mark et al. (2012) describe monitoring of subsidence caused by tunnelling in an urban environment detecting displacement rates in the range of a few millimetres per year. In Germany more and more sites of public interest such as the cities of Staufen, Landau and Boeblingen are being (or recently have been) surveyed via satellite-based InSAR (Lubitz et al. 2013; Airbus DS 2014). Thus, many objects distributed over wide areas may be monitored, as shown e.g. by Ciampalini et al. (2014), under most weather conditions regardless of optical visibility and cloud cover. Deformation history over more than 20 years may also be studied using archived radar data. The identifiable object size scale, typically 2 to $20 \mathrm{~m}$, enables the detection and measurement of displacement changes even at relatively small parts of a building. This capability is improving while even higher measurement density and accuracy are becoming available with advanced radar modes and data processing strategies (e.g. DLR 2013).

In this paper, practical experience with the application of processed InSAR data is described from a user's point of view. It is intended to identify benefits as well as considerations of this technique and provide some guidance in order to avoid possible foreseeable pitfalls, focussing on operational monitoring of civil engineering applications.

\section{Hessigheim navigation lock}

Hessigheim lock structure is situated on the river Neckar north of Stuttgart, Germany. Lock \#1, weir and powerhouse were constructed in 1950/51. Lock \#2 was added about ten years later. The community of Hessigheim at the right bank of the river is located directly adjacent to the locks. Each lock chamber's usable length is $110 \mathrm{~m}$ with a clear width of $12 \mathrm{~m}$ and lifting height of $6.2 \mathrm{~m}$. A powerhouse, a small residential area and several greenhouses can be recognised on the left bank of the river in Figure 1.

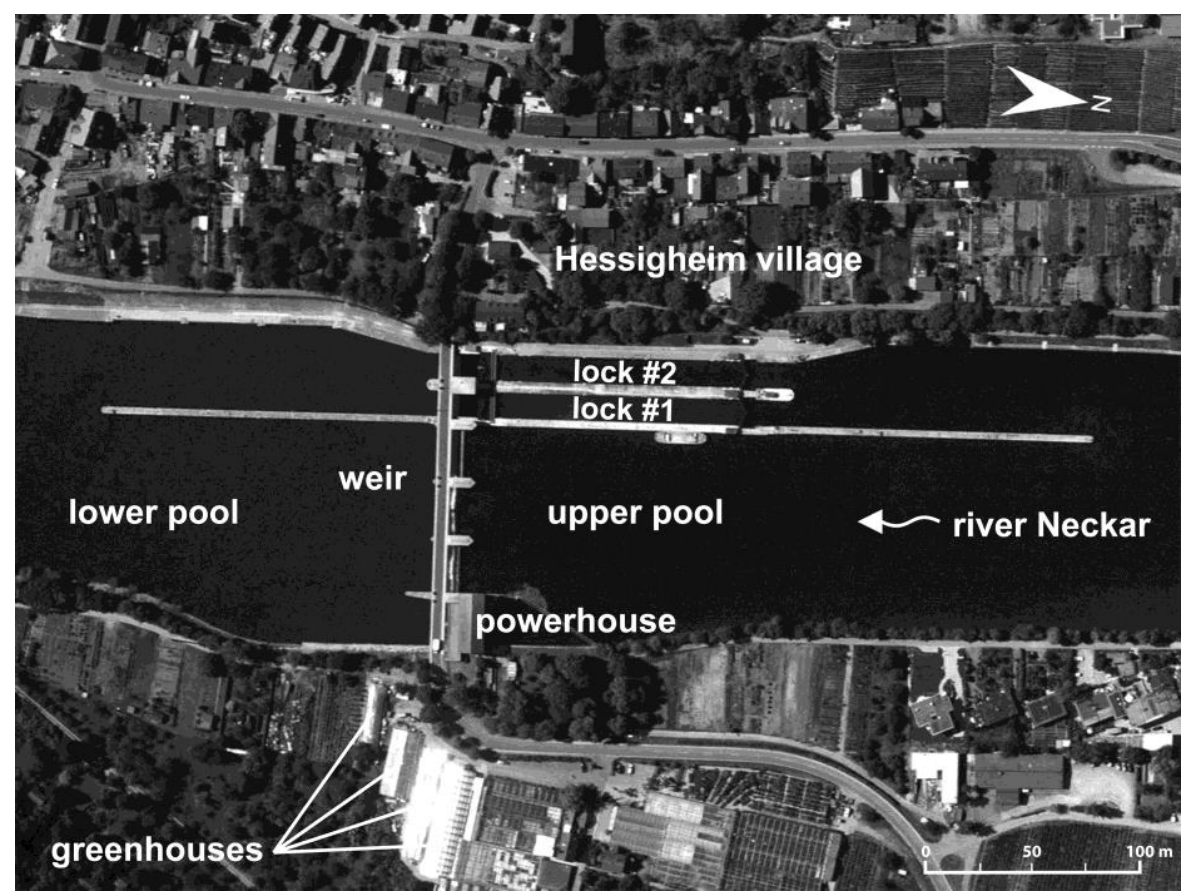

\section{Figure 1 Aerial view of Hessigheim lock structure and vicinity}

Rocks of the so-called Middle Muschelkalk (shell-bearing limestone) are in place in the Neckar basin in the Hessigheim area. A simplified cross-section (together with the structure of the upper gate of the second lock) showing the local subsoil conditions is depicted in Figure 2. From bottom to top, we differentiate a lower sulphate layer and a lower dolomite layer, which is overlain by a rock salt deposit. The following upper sulphate layer is composed of an upper and lower clay anhydrite layer, divided by a distinctive layer of intermediate dolomite, which is only a few metres thick. Above the rock, soil layers exist, consisting of river gravel ('Neckar gravel') and engineered fill. According to lab tests the upper clay anhydrite consists of 
87 to $99 \% \mathrm{CaSO}_{4}$ (gypsum) and the lower clay anhydrite of $67 \% \mathrm{CaSO}_{4}$ on average. As a consequence, because of the solubility of gypsum in water the upper clay anhydrite is in large parts strongly weathered, leached and comprises numerous voids. These voids are partially filled with Neckar gravel and boulder that migrated from above into the voids. The weathered upper clay anhydrite consists of cohesive material with soft to stiff consistency resting on the leached karst base level and is called residual clay. Such underground conditions are prone to form sinkholes, which occasionally occurred in the Hessigheim area before, during and after the installation of the lock structures. Such sinkholes tend to develop over many years, as the covering sediment migrates into open voids of the weathered sulphate layer. Often, soil movements associated with developing voids are only detected by the deformation of engineering structures.

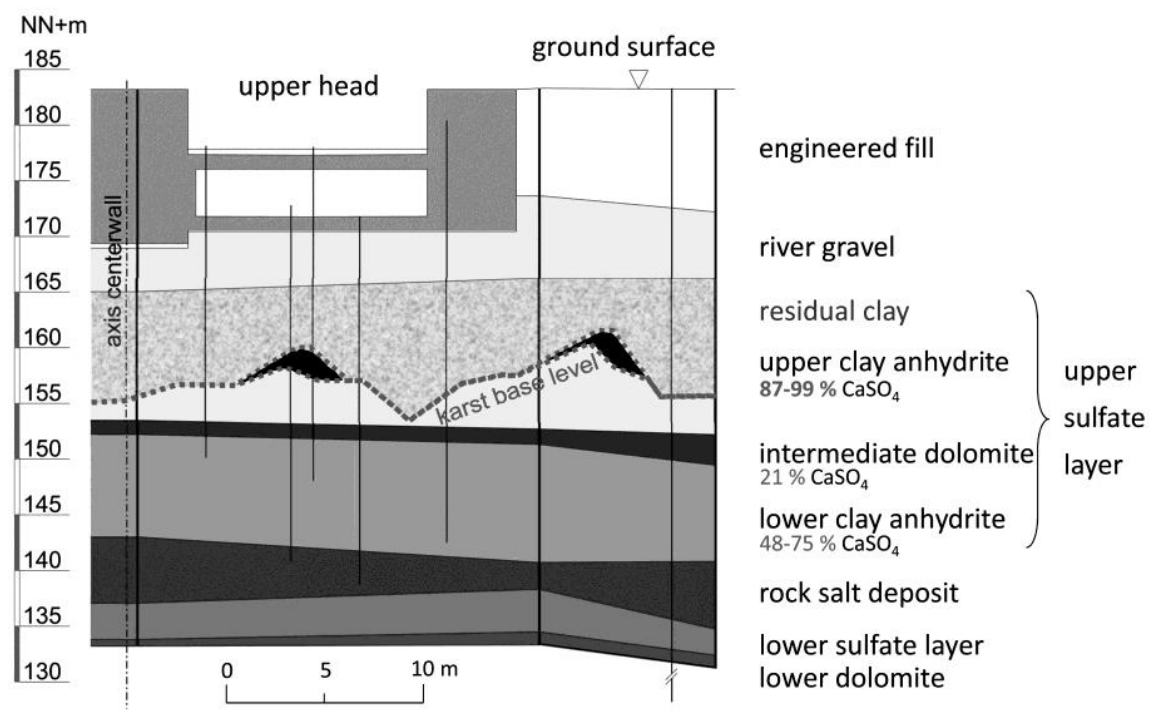

\section{Figure 2 Characteristic geologic cross-section}

A comparison of the drilling campaigns of 1950/60 with 1991/93 shows a vertical progression of the karst base level at a rate of approx. $0.1 \mathrm{~m} / \mathrm{y}$ in the area of the locks. These leaching processes in the subsoil have led to considerable displacements of the lock structure since construction. The lock structure was eventually completely rehabilitated by grouting the underground voids with cement slurry in the 1980s underneath the locks, weir and powerhouse. Background information on the entire project is provided in Bergholz et al. 2011.

As a consequence of the leaching processes, the civil engineering structure has been extensively monitored since 1970. The monitoring program consists of groundwater observations, vertical and horizontal geodetic measurements as well as extensometer measurements, all performed at least at yearly intervals. Figure 3 provides an example of the layout of geodetic measurements showing locations of measurement points along the locks.

Irregular displacements were detected at the landward walls of the right upper head and of lock \#2 in 2005. The walls were tilting considerably towards the backfill which was observed by alignment measurements. These deformations are still continuing. Because this kind of tilting was not readily explainable, all available geodetic data was analysed. As a result, additional areas were identified, where further investigation seems to be necessary:

- Geodetic levelling data on the landside of lock \#2 indicate a settlement trough behind the chamber wall with a relative maximum at the levelling points 218 and 219 (Figure 3).

- Considerable and continuous settlements are also being observed for the concrete wall upstream of the upper head (corresponding levelling points are 100, 200, 300 and 400), which is separated from the rest of the upper head gate wall by a joint. Further investigation has shown that the subsoil of this wall was not part of the former grouting works (Figure 3 ). 
- Considerable and continuous tilting is being observed at the powerhouse.

- Considerable and continuous settlements are being observed at the greenhouses.

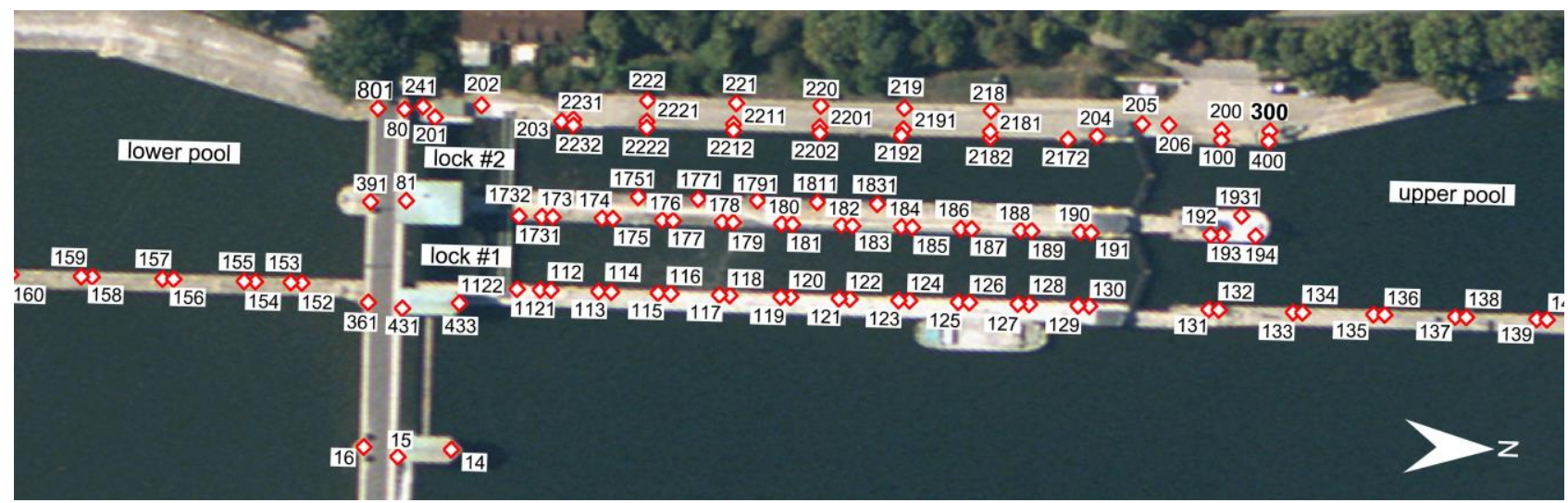

Figure 3 Layout of geodetic measurements in the area of the locks

Increased and continuous leaching in the neighbourhood of the grouted areas is suspected to be the explanation for the deformations described above. Groundwater modelling was performed including calibration using existing groundwater measurements. The calculation results indicate that groundwater flow has been modified due to the grouting efforts, concentrating the flow landwards behind the upper head and parallel to the lock wall. Thus, increased and continuous leaching may be anticipated at regions where groundwater flow is intensified. With this explanation, an area with continuous settlement should be expected further upstream. Unfortunately, past geodetic observations are not available for this area of special interest. Here is where InSAR measurements came into play.

Due to the lack of measurements in that specific area, the possibility was evaluated to fill the missing geodetic data with InSAR combined with advanced processing methods. By using InSAR, the detection of extent and development of the possibly forming sinkhole with time seemed to be achievable in the sense of a rear-view mirror. As a side benefit, validation of the radar measurements could be obtained without much additional effort, because the geodetic measurements since 1970 were readily available.

\section{$3 \quad$ InSAR measurements and PSI processing}

InSAR is a proven remote sensing tool. A side-looking radar sensor on board of a satellite emits microwaves and detects signals which are reflected from scatterers on the surface of the earth. Intensity as well as the phase of the reflected signal is measured. By comparing two radar scenes 'interferograms' are produced, which contain information on the phase difference between both scenes. This phase shift, directly related to the wavelength of the radar signal, is associated with the displacement to be measured. Further information on basic principles of InSAR measurements is given e.g. by BSRSI (1999) or Jackson et al. (2004).

The time-series processing method called Persistent Scatterer InSAR (PSI) was developed at the Technical University of Milano (POLIMI) by Ferretti (1997). In order to minimise measurement uncertainty, the method exploits statistical effects using a stack of radar scenes. In the following years, the method has been modified and improved by many others. Practical guidance on PSI is given by Bateson et al. (2010), for more details see Ferretti et al. (2007), Kampes (2006) or DMV (2013). Meanwhile this tool can be regarded as sufficiently developed for use especially in urban areas for civil engineering purposes, e.g. for preservation of evidence. Processing radar data to detect subsidence is already described in detail by Ketelaar (2009), looking at displacements occurring over much larger areas. Here we focus on selected aspects regarding the detection of subsidence on the scale of civil engineering structures.

Since InSAR performed using a single satellite track is limited to detecting displacements in the radar line-of-sight (LOS), it should be assessed if the expected specific movement is generally detectable from the chosen track. For this evaluation, the direction of the beam (LOS) is decisive, and the flight direction can be 
used as a proxy. For the area of interest in this study, the flight path of radar satellites is approximately from north to south ('descending') or from south to north ('ascending'), with the radar sensor looking towards the right hand side of the flight path. Thus, the LOS is approximately towards east for an ascending flight path, and towards west for a descending flight path.

InSAR is most suitable for detecting continuous and slow movements. When comparing two radar scenes, unambiguous displacement differences are limited to $\pm \lambda / 4$ (i.e. a total of half the wavelength $\lambda$ ) between corresponding measurement points. If larger displacement differences occur within one orbit repeat cycle (i.e. between two consecutive radar scenes), usually the displacement can be detected but not necessarily measured unambiguously. Therefore, the repeat cycle is decisive in the correct choice of satellite for the deformation phenomenon being measured.

The output of InSAR data processing is a set of PS points, which is usually presented as colour-coded dots overlaid on maps or orthophotos. A time/displacement diagram is available for each PS to allow in-depth analysis of the behaviour of selected PS. In this paper, the originally colour-coded dots are converted to grayscale. Heave (positive displacement rate in LOS) is represented by darker dots, settlement (negative displacement rate in LOS) by lighter dots and minor subsidence (neutral) by grey dots. The number of identified PS primarily depends on the phase quality (coherence) of the backscatter signal of the observed object, which is also directly related to the amplitude stability of a bright scatterer. It is also influenced by the applied processing algorithms, the resolution of the radar sensor and various other parameters. PS density is higher in urban areas with man-made infrastructure, than in rural areas with thick vegetation. However, the exact quantity and locations of PS cannot be predicted in advance, and can only be determined by processing radar scenes.

As a first step, availability of archived scenes was assessed for the area of Hessigheim. Sufficient numbers of radar scenes were found at the European Space Agency (ESA) data archives. The scenes were acquired by the satellites ERS-1 and ERS-2 (1992 to 1997) as well as Envisat (2004 to 2008). In a further step, newly acquired TerraSAR-X (TSX) scenes were included to supplement the study. Standard resolution data from ESA is available free of charge, unlike data with higher resolution (e.g. TerraSAR-X or Cosmo Skymed).

\section{$4 \quad$ Results of data comparisons}

Obtaining radar data, processing the radar images and detecting deformation in the surroundings of the lock Hessigheim were carried out by SkyGeo (formerly called Hansje Brinker), a consultant with specialised expertise in InSAR processing (Schouten \& Leezenberg 2012; Schouten 2013).

\subsection{ERS and Envisat}

In a first step radar scenes acquired by the satellites ERS-1 and ERS-2 were analysed in order to try looking back in time. 42 radar scenes from November 1992 to September 1997 were downloaded from ESA data archives and analysed using PSI technique. Only about 300 persistent scatterers per square kilometre $\left(\mathrm{PS} / \mathrm{km}^{2}\right)$ were identified at the lock structure and the neighbouring built-up area. In the area of the greenhouses, the density increased to about $1,100 \mathrm{PS} / \mathrm{km}^{2}$.

In a second step, 17 radar scenes of Envisat covering the period from October 2004 to September 2008 were processed. The density of persistent scatterers was found to be similar to that from ERS data. Results of PSI analysis of ERS data are depicted in Figure 4 and Envisat data in Figure 5. As described in Chapter 2, continuous settlements have been observed in the area of the upstream wall of the right upper head (levelling points 100, 200, 300 and 400). In this area also a PS was identified, which is labelled ' $A$ ' in Figures 4 and 5. 


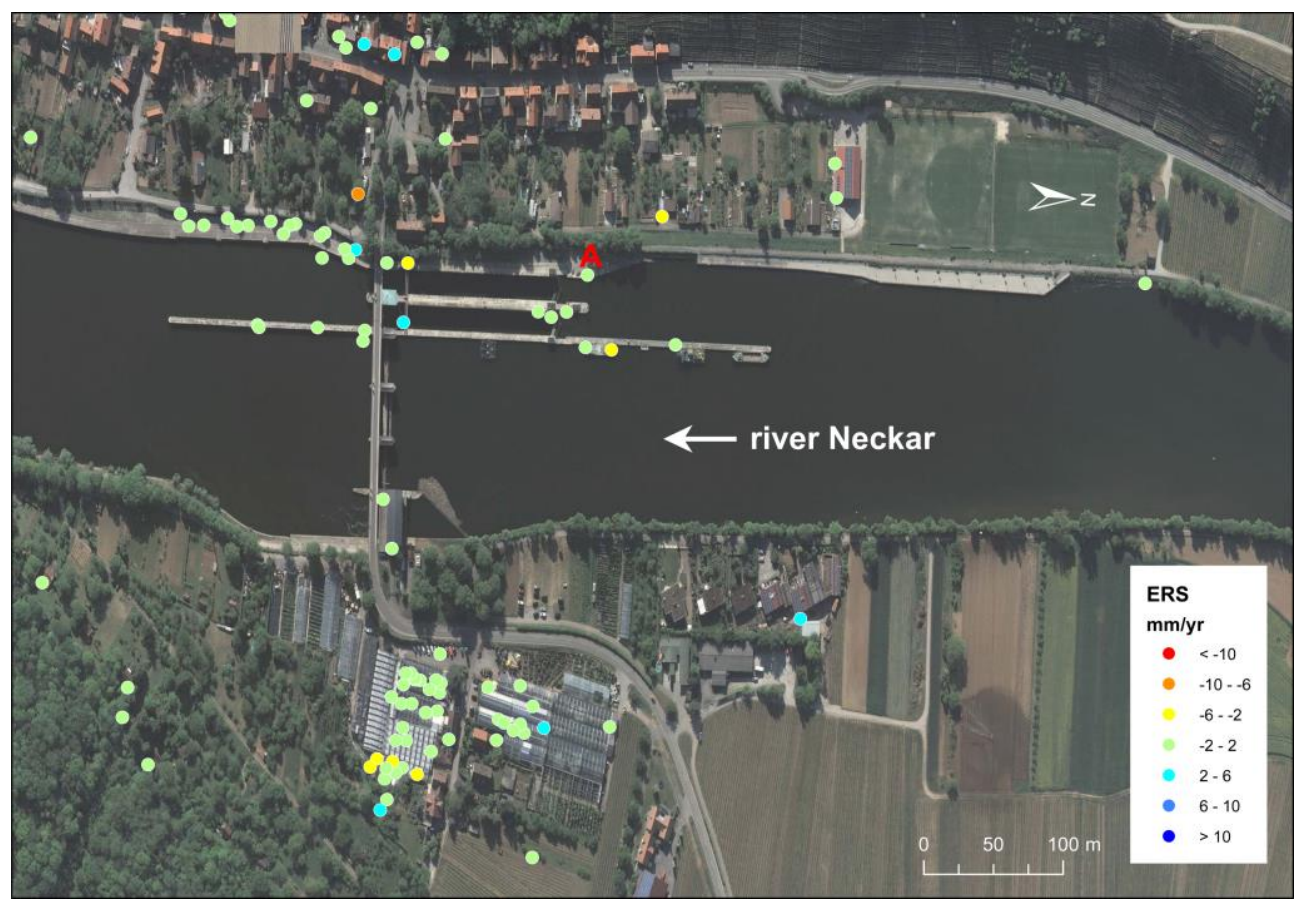

Figure 4 PSI analysis of ERS scenes (standard resolution $4 \times 20 \mathrm{~m}$ ): deformation rate

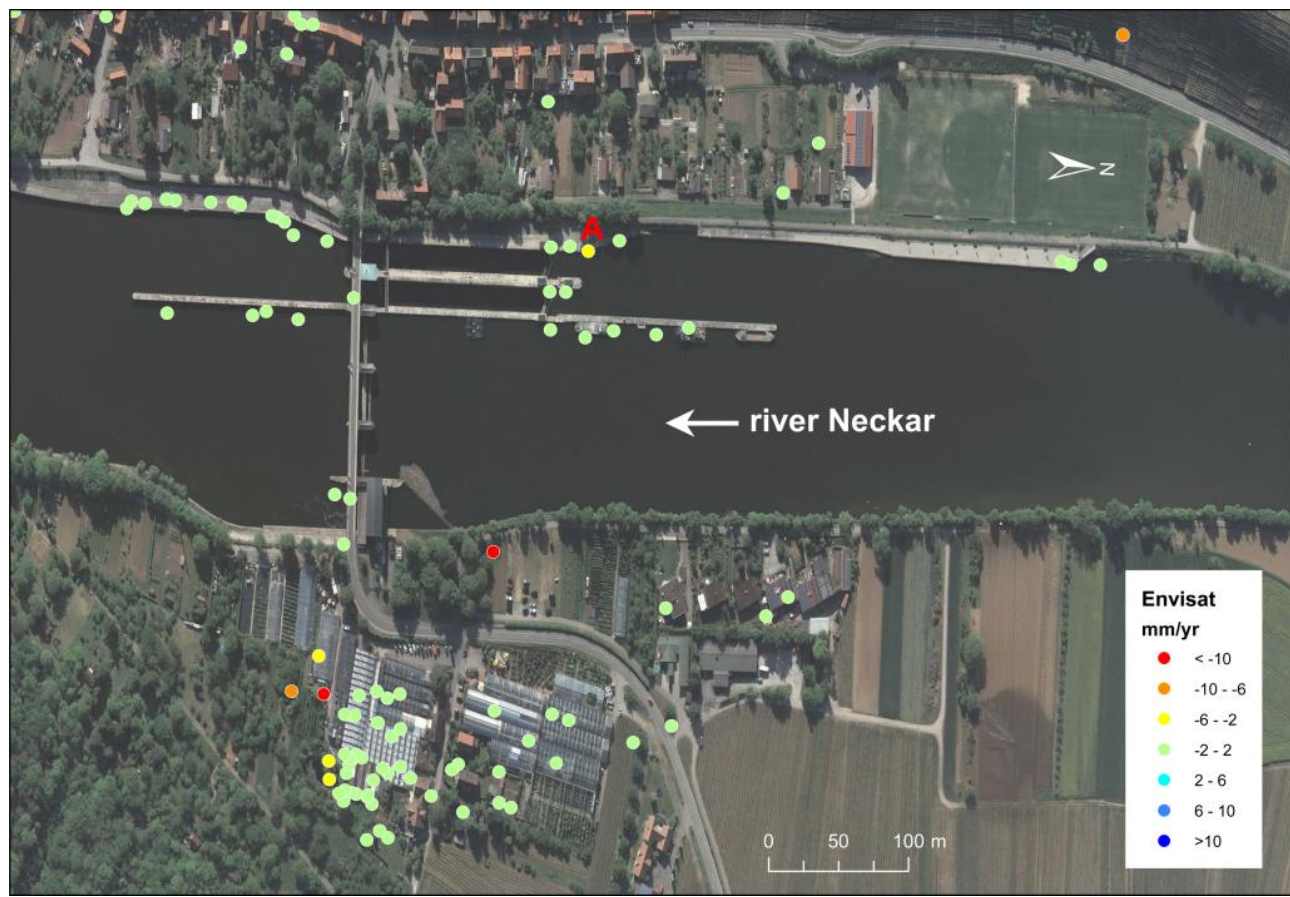

Figure 5 PSI analysis of Envisat scenes (standard resolution $4 \times 20 \mathrm{~m}$ ): deformation rate

PSI analysis was done using mainly descending radar scenes. Analysis of both data sets (ERS and Envisat) resulted in a relatively low number of PS in the areas of interest (landward the lock, lock walls, powerhouse, greenhouses). In order to increase the number of PS, in a further step additional ascending radar scenes have been analysed, with limited success in areas mentioned above. Three major drawbacks were identified as probable reasons:

Resolution of the radar scenes of $4 \times 20 \mathrm{~m}$ is relatively low. 
Pixel orientation of the radar scenes is unfavourable $(4 \mathrm{~m}$ measured along flight track and $20 \mathrm{~m}$ in cross-track direction). Thus, an increased probability exists of water surfaces covering a significant part of the resolved pixel; with $20 \mathrm{~m}$ resolution in the east-west direction, the wall cannot be separated from the interior of the lock chamber basins.

Apparently, shipping traffic in the locks prevents the identification of PS right next to the lock chamber. This idea is supported by two aspects: Firstly, commercial ship vessels are very strong reflectors because they are made out of steel and carry an effective radar reflector on the upper deck. Secondly, the ship traffic stops during the time of transit, while the vessel occupies a major area of the lock chamber. Thus, the probability is increased, that a ship is occupying the lock chamber during the moment of acquiring the radar scene. This leads to strong backscatter by the vessels, interfering with nearby pixels and preventing them from registering as coherent scatterers in the PSI algorithm.

All these effects contribute to prevent the identification of PS along the lock chamber walls.

Next, validation of the processed radar data was performed by comparing the results with long term geodetic levelling measurements. In Hessigheim, two locations were considered for investigation. In the area of the greenhouses, substantial subsidence had been identified. Additionally, subsidence of much lesser extent was measured at the right upper head. Since geodetic levelling was available in very close proximity to the identified PS at the upper head, levelling point 300 has been selected for further evaluation (Figure 6). During the time period from October 1992 to September 2010, levelling point 300 (Figure 3) has settled relatively steadily at about $1.2 \mathrm{~mm} / \mathrm{y}$ on average, in the vertical direction. This average rate of displacement is used to compare displacements of processed radar data represented by the identified PS located at region 'A' (Figures 4 and 5).

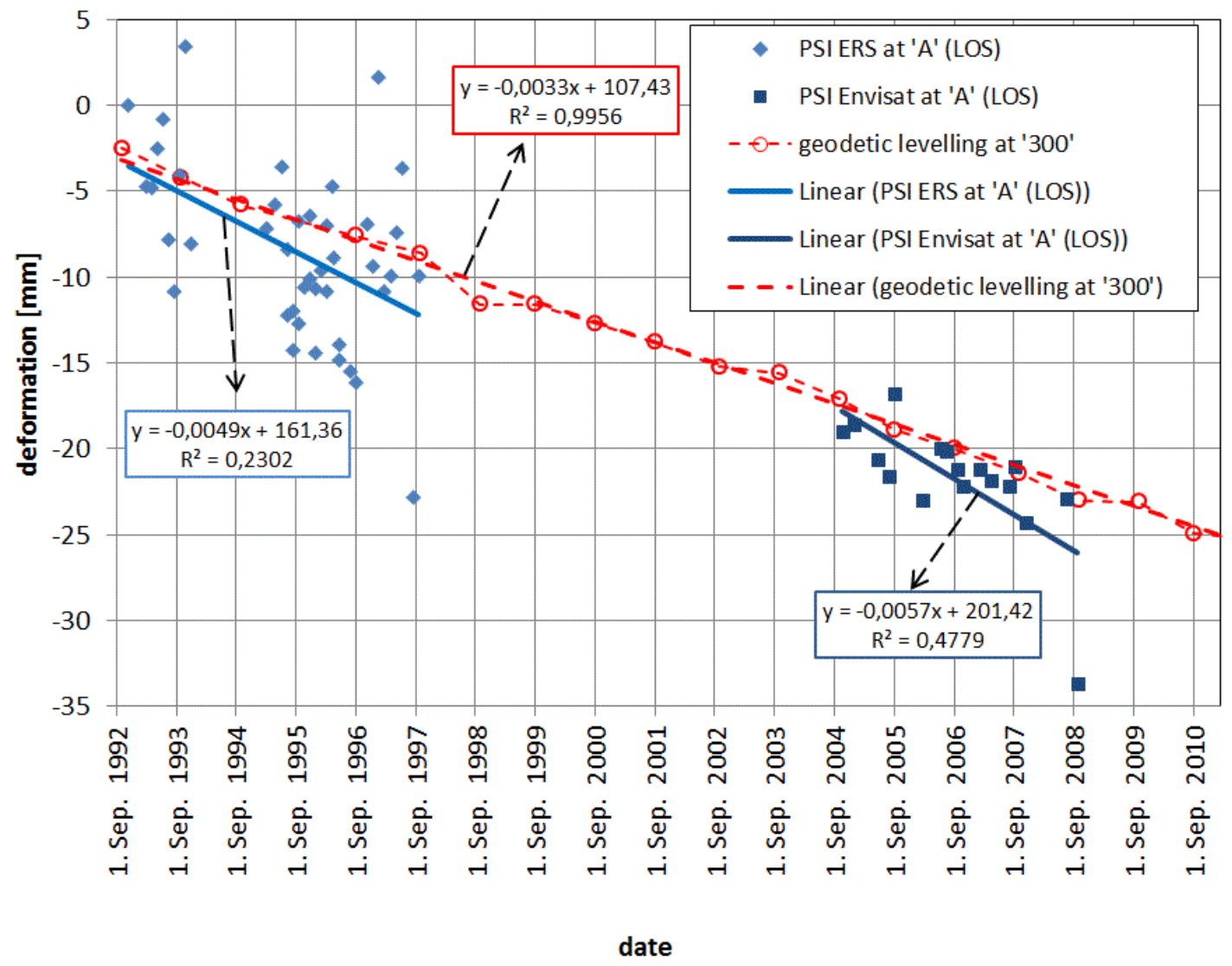

\section{Figure 6 Deformation from PSI analysis of ERS and Envisat data compared to geodetic levelling}

Results from two PSI analyses are also included in Figure 6, representing LOS-deformation characteristics at point ' $A$ ' also located at the lock's left upper head. Each of the straight lines labelled 'Linear' has been 
derived from simple linear regression (least squares approach). Processed satellite data of ERS (from November 1992 to September 1997) show a displacement rate, which is slightly greater than (but very similar to) the rate measured by geodetic levelling. The same applies to a second data set of Envisat (from October 2004 to September 2008). If the radar-detected displacement rates are corrected via incidence angle assuming a purely vertical displacement of the upper head, the displacement rate approaches the geodetic results even further. Although considerable scatter is present in both PSI analyses (correlation coefficient expressed as squared Pearson's R included in Figure 6), analysis of Envisat data apparently leads to significantly less scatter than ERS data, acquired a few years earlier. The results indicate a sufficient validation of the displacement rate of Envisat data measured by InSAR compared to the long-term displacement rate measured by conventional geodetic means. Although analysis of ERS data shows a displacement rate similar to Envisat analysis, ERS results provide a low correlation coefficient (Pearson's $\mathrm{R}=0.48$ ) indicating large scatter which may be not acceptable.

Generally it is concluded, that InSAR data reaching back to 1991/1992 may be used to gain information on subsidence effects like using a rear view mirror. However, significant limitations in resolution when using ERS/Envisat data need to be accounted for as far as civil engineering applications are concerned.

It should also be emphasised that all PS of interest were inspected in situ to avoid misleading interpretations.

At Hessigheim, the lock structure is embedded in a built-up area, which represents a typical situation at inland waterways in Germany. In order to test the potential of higher resolution radar scenes it was decided to proceed with data acquired by the satellite TerraSAR-X. By this decision, an additional aspect has been included: to gain insight by applying InSAR in order to assist preservation of evidence.

\subsection{TerraSAR-X: StripMap (SM)}

The satellite TerraSAR-X (TSX) can acquire radar scenes in several modes. An example of a high resolution mode is StripMap (SM), with a ground resolution of about $3 \times 3 \mathrm{~m} .26$ radar scenes recorded in SM-mode were acquired during 18 months from February 2013 to July 2014 at a scheduled time interval starting with 11 days, later thinning to 22 days and more.

PSI analysis identified about 5,400 persistent scatterers per square kilometre (PS/ $\left.\mathrm{km}^{2}\right)$ at the lock structure and the neighbouring built-up area (Figure 7), at the area of the greenhouses the density increased to about 7,000 PS/ $/ \mathrm{km}^{2}$. Compared to ERS/Envisat this represents a broad increase in the number of PS, which allows identifying displacements at a scale down to sub-building size. As a consequence, several PS were identified in the area of the right upper head, now labelled ' $B$ ' in Figure 7. Those PS show displacement rates in the range of $-0.1 \mathrm{~mm} / \mathrm{y}$ (settlement) to $+0.5 \mathrm{~mm} / \mathrm{y}$ (heave). Assuming an average displacement rate of $-1.2 \mathrm{~mm} / \mathrm{y}$, a total displacement of $-1.8 \mathrm{~mm}$ is to be expected at levelling point 300 during the observation time of 18 months. Since the measurement uncertainty is within a couple of millimetres per epoch, the expected displacement of a mere $1.8 \mathrm{~mm}$ is within the measurement error bar. Therefore, the result of SM-data processing can be regarded to be correct within the measurement uncertainty. For definitive validation, a much longer observation period would be required.

Data scatter at time-displacement graphs of processed TSX-SM data remains at a satisfying low level comparable to the results of Envisat data analysis. 


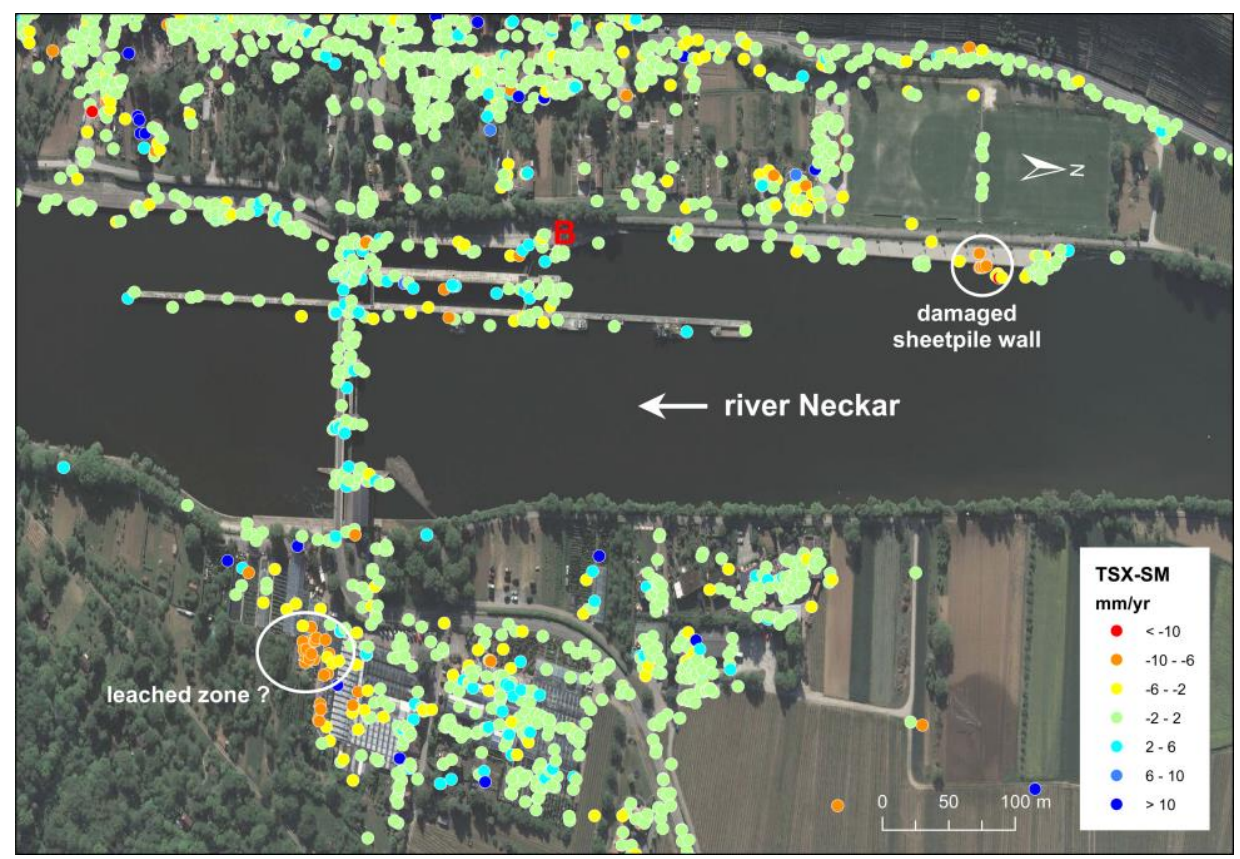

Figure 7 PSI analysis of TSX-SM scenes (resolution $3 \times 3 \mathrm{~m}$ )

As shown in Figure 7, the processed SM-data has enabled the identification of additional displacements, e.g. a defective sheet pile wall at the right upper pool serving as ship waiting area. Presumably, the sheet pile wall was also damaged by geological leaching; for confirmation, further in situ investigation is required. It may be observed that some of the PS appear to be located slightly off the lock structures. This may be attributed to (1) the geocoding accuracy (up to $1 \mathrm{~m}$ ) of InSAR using TSX-SM, and (2) the geocoding accuracy of the optical imagery used for visualisation.

In the area of the greenhouses, on the left side of the river a short distance downstream of the powerhouse, the large number of PS confirms an area of subsidence already identified by ERS and Envisat. The detected displacement rate in the order of 6 to $10 \mathrm{~mm} / \mathrm{y}$ can be interpreted under geologic aspects as a zone of leaching of the highly soluble gypsum rock. Further geotechnical investigation is planned to verify this presumption in order to assess the true cause.

\section{TerraSAR-X: spotlight modes and future prospects}

Compared to TSX-SM, the spotlight modes of TSX provide an even better resolution resulting in a significantly increased density of PS (Reale et al. 2011). A drawback may be a decreased swath, covering less area per radar scene. Nevertheless, the area covered per scene (max. $10 \times 10 \mathrm{~km}$ to $\min .4 .6 \times 2.8 \mathrm{~km}$ ) should be more than sufficient for most civil engineering applications. The spotlight modes achieve a higher resolution by slightly rotating the radar beam while temporarily focussing on the area of interest. Two spotlight modes are currently available: High-resolution spotlight (HS) at a resolution of about $1 \times 1 \mathrm{~m}$ and staring spotlight (ST) at an even better resolution. To process such InSAR data advanced algorithms are necessary, requiring high processing competence. Details on those very high resolution modes of TSX may be found in DLR (2013) and Mittermayer et al. (2014).

TSX-HS scenes ( $300 \mathrm{MHz}$ range bandwidth option) are currently being collected over the Hessigheim area and are being processed. Figure 8 shows preliminary results of the two modes of TSX interferograms over Hessigheim. Colour levels represent phase values in the interferograms, wrapped within the interval $-\pi$ to $+\pi$ radians. Deformation cannot be directly inferred from these values, but they give a preliminary indication of the level of coherence and the difference in resolution between the two modes. Better coherence and greater detail imply a higher density of PS measurements. In the visualisation of the HS mode $(1 \times 1 \mathrm{~m}$ pixel resolution), smaller coloured dots have been chosen than in the SM mode $(3 \times 3 \mathrm{~m}$ 
pixel resolution). The slightly varying area and scale are due to the different viewing geometry (incidence angle) of the two satellite modes.

Since the resolution of $1 \mathrm{~m} \times 1 \mathrm{~m}$ matches the size of many man-made objects or even parts of building structures (Figure 8), a high potential for preservation of evidence can be expected. It is necessary to gain further experience concerning the possibilities of such a technique. Follow-up missions of TSX are already scheduled. It may be expected, that high resolution and very high resolution InSAR data will be available beyond the life time of the currently active TSX satellites.

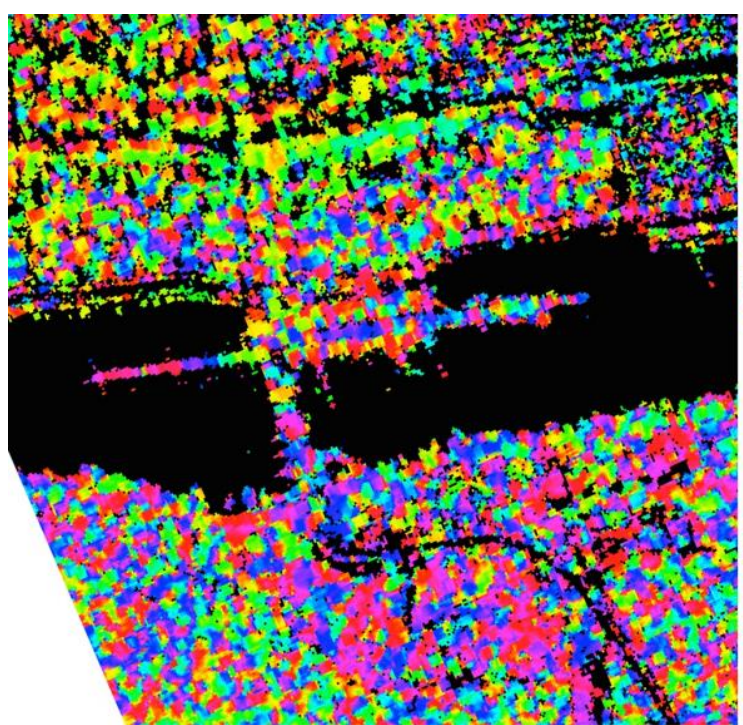

(a)

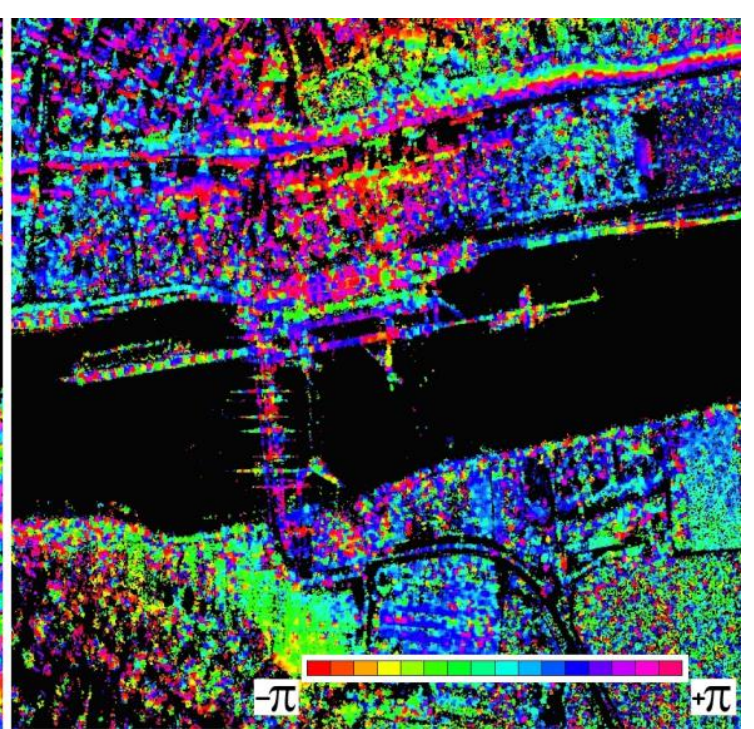

(b)

Figure 8 TSX interferograms: (a) SM mode (resolution $3 \times 3 \mathrm{~m}$ ); (b) HS mode (resolution $1 \times 1 \mathrm{~m}$ ); (colour levels represent phase values in the interferograms)

\section{$6 \quad$ Lessons learned and remarks}

In BAW, the tool of InSAR has been applied for the first time concerning detection of subsidence in sub-centimetre to millimetre range on the scale of civil engineering structures. From a user's point of view, the following topics should be considered:

In the project described above, a stack of at least 20 scenes (radar images) was required for measurements of subsidence. Because of pre-determined repeat cycles (e.g. 11 days for TSX) of the selected satellite, the time taken to acquire the required number of scenes needs to be kept in mind. It could also (rarely) happen that pre-ordered scenes might be skipped due to priority decisions of the satellite operator. Longer than scheduled revisit time also limits the maximum detectable rate of displacement and may delay decisions based on the measured displacements.

Detection and measurement works better for the following:

- Relatively slow displacement depending on radar wavelength $\lambda$ ( $\Delta s \leq \lambda / 2$ per revisit).

- Continuous displacements in LOS of the radar sensor.

- Difficulties may arise analysing.

- Areas covered with vegetation.

- Surface of water bodies or wetlands or areas covered by snow.

- Areas with considerable traffic (e.g. car, ship).

The ground range resolution of radar data provided by satellites such as ERS, Envisat or Sentinel-1 may not be detailed enough for some applications in civil engineering, especially at building-level. Higher resolution 
is currently supplied by TerraSAR-X or Cosmo-SkyMed satellites. Although strip map modes may suffice, very high resolution modes (e.g. spotlight) show much more details and provide significantly higher PS density - if proper processing of such data can be provided. This is currently an active area of investigation. Such high resolution modes may assist preservation of evidence linked to displacements generally caused by construction activity.

InSAR information can be used to identify locations ('hot spots', such as the presumed leaching zone at the greenhouses) where further site investigation may be required. Thus, site investigation can be concentrated at such pre-selected 'hot spots' leading to improved insight compared to a conventional trial and error approach - such an approach would cover the entire area of the project with a good chance of missing local anomalies entirely. InSAR can complement geodetic/geotechnical methods, which then may be deployed more selectively and efficiently.

As a rule, it is recommended to verify the plausibility of suspected areas on site as displacements detected by radar data may have a series of trivial causes.

\section{$7 \quad$ Conclusion and outlook}

InSAR data provided by ESA, reaching back to 1991 may be used to gain information on subsidence effects like a rear view mirror. However, significant limitations in resolution need to be accepted as far as civil engineering applications are concerned. Using radar data of higher resolution combined with PSI analysis proved to be capable of detecting displacement changes at civil engineering structures like the Hessigheim lock. Validation of displacement rates measured by radar compared with long-term displacement rates measured with conventional geodetic levelling indicated sufficient agreement.

As a consequence, high resolution InSAR data could assist preservation of evidence associated with construction of large infrastructure at waterways and elsewhere. TSX-HS scenes are currently being collected of the Hessigheim area for future analysis and reporting.

\section{Acknowledgement}

We thank Waterways and Shipping Office Stuttgart (Wasser- und Schiffahrtsamt), Amt für Neckarausbau Heidelberg and SkyGeo (formerly Hansje Brinker), Delft, the Netherlands for their assistance.

\section{References}

Airbus DS - Infoterra GmbH 2014, 'Satellitenbasierte Bodenbewegungsmessung in Landau in der Pfalz, Deutschland', prepared by J Anderssohn, Munich, Germany.

Bateson, L, Novali, F \& Cooksley, G 2010, Terrafirma user guide, GMES Terrafirma, viewed 22 May 2015, http://www.terrafirma.eu.com/images_all_site/documents/user_guide/Terrafirma\%20User\%20Guide\%200ct\%202010.pdf

Bergholz, K, Kauther, R, Montenegro, H \& Straßer, D 2011, 'Grundwasserinduzierte Veränderungen im lösungsempfindlichen Baugrund unterhalb der Schleusenanlage Hessigheim am Neckar', Proceedings BAW-Kolloquium - Aktuelle geotechnische Fragestellungen bei Baumaßnahmen an Bundeswasserstraßen, Bundesanstalt für Wasserbau, Karlsruhe, Germany, pp. 13-26.

BSRSI 1999, 'Introduction to microwave remote sensing', prepared by D Lusch, Basic Science and Remote Sensing Initiative, Michigan State University, MA.

Ciampalini, A, Bardi, F, Bianchini, S, Frodella, W, DelVentisette, C, Moretti, S \& Casagli, N 2014, 'Analysis of building deformation in landslide area using multisensory PSInSAR technique', International Journal of Applied Earth Observation and Geoinformation, vol. 33, pp. 166-180.

DLR 2013, TerraSAR-X ground segment basic product specification document, DLR, Cologne, viewed 22 May 2015, https://tandemxscience.dlr.de/pdfs/TX-GS-DD-3302_Basic-Products-Specification-Document_V1.9.pdf

DMV 2013, Grundsätze zum Einsatz von satellitengestützten Verfahren dēr Radarinterferometrie zur Erfasssung von Höhenänderungen, Deutscher Markscheider-Verein e.V. (DMV), viewed 18 November 2013, http://www.dmvev.de/component/attachments/download/69.html

Ferretti, A 1997, 'Generazione di mappe altimetriche da osservazioni SAR multiple', PhD thesis, Politecnico di Milano.

Ferretti, A, Monti-Guarnieri, A, Prati, C \& Rocca, F 2007, InSAR principles: guidelines for SAR interferometry processing and interpretation (TM-19), European Space Agency ESA Publications, Noordwijk, Netherlands.

Fornaro, G, Reale, D \& Verde, S 2013, 'Bridge thermal dilation monitoring with millimeter sensitivity via multidimensional SAR imaging', IEEE Geoscience and Remote Sensors Letters, vol. 10, no. 4, pp. 677-681. 
Gernhardt, S, Cong, X, Eineder, M, Hinz, S \& Bamler, R 2012, 'Geometrical fusion of multitrack PS point clouds', IEEE Geoscience and Remote Sensors Letters, vol. 9, no. 1, pp. 38-42.

Jackson, C \& Apel, J (eds) 2004, Synthetic aperture radar marine user's manual, US Dept. of Commerce and National Oceanic and Atmospheric Administration (NOAA), Washington DC.

Kampes, B 2006, 'Radar interferometry: persistent scatterer technique', Springer Science + Business Media B.V., Dordrecht, Netherlands.

Ketelaar VBH 2009, 'Satellite Radar Interferometry - Subsidence Monitoring Techniques', Remote Sensing and Digital Image Processing, Springer Science + Business Media B.V., Dordrecht, Netherlands.

Lubitz, C, Motagh, M, Wetzel, H \& Kaufmann, H 2013, 'Remarkable urban uplift in Staufen im Breisgau, Germany: observations from TerraSAR-X InSAR and leveling from 2008 to 2011', Remote Sensing, vol. 5, no. 6, pp. 3082-3100.

Mark, P, Niemeier, W, Schindler, S, Blome, A, Heek, P, Krivenko, A \& Ziem, E 2012, 'Radarinterferometrie zum Setzungsmonitoring beim Tunnelbau', Bautechnik, vol. 89, no. 11, pp. 764-776.

Mittermayer, J, Wollstadt, S, Prats-Iraola, P \& Scheiber, R 2014, 'The TerraSAR-X staring spotlight concept', IEEE Transactions on Geoscience \& Remote Sensing, vol. 52, no. 6, pp. 3695-3706.

Reale, D, Fornaro, G, Pauciullo, A, Zhu, X \& Bamler, R 2011, 'Tomographic imaging and monitoring of buildings with very high resolution SAR data', IEEE Geoscience and Remote Sensing Letters, vol. 8, no. 4, pp. 661-665.

Schouten, M 2013, 'Hessigheim-Besigheim sluice complexes in der Neckar River - first results of high-resolution deformation monitoring 2013-2014', unpublished report by Hansje Brinker BV, Delft.

Schouten, M \& Leezenberg, PB 2012, 'InSAR deformation measurements of the Hessigheim waterway complex (1992-2010)' unpublished report by Hansje Brinker BV, Delft. 